\title{
Suprarenal gland hemorrhage: A bleeding manifestation that may be caused by thrombosis of efferent veins
}

\author{
Antonio Girolami ${ }^{1 *}$, Elisabetta $\operatorname{Cosi}^{1}$, Silvia Ferrari ${ }^{1}$, Bruno Girolami ${ }^{2}$ and Maria Luigia Randi ${ }^{1}$ \\ ${ }^{1}$ Department of Medicine, University of Padua Medical School, Padua, Italy \\ ${ }^{2}$ Division of Medicine, Padua City Hospital, Padua, Italy
}

\begin{abstract}
Suprarenal gland hemorrhage has been described in several conditions (sepsis, local traumas, surgical procedures, anticoagulant therapies, ACTH administration, protracted stress, hypoxemia). The condition is rare in congenital bleeding disorders. Recently, two new morbid conditions, namely Heparin induced thrombocytopenia and Antiphosfolipids Antibodies Syndrome have been reported as frequent causes of suprarenal gland bleeding. The condition may be classified as monolateral or bilateral. The first is usually paucisymptomatic, the latter, severely symptomatic. The causative mechanisms are two, namely 1 ) direct congestion and damage of the gland with secondary leakage of blood and consequent cell destruction and 2) thrombosis of efferent veins with consequent upstream increased pressure and rupture of vessels. The first mechanism, direct cellular insult is typical of most of the old cases. On the contrary, the thrombotic occlusion of efferent veins is typical of the new morbid conditions, namely Heparin induced thrombocytopenia, Antiphospholipids Antibodies Syndrome and Polycythemia vera. This second mechanism could be envisaged as an example of thrombo-hemorrhagic disorder. An idiopathic form has also been described. The variety and complexity of causes have great implications in diagnostic procedures, therapeutic approaches and outcomes.
\end{abstract}

\section{Introduction}

Bleeding is usually an overt event involving skin, mucosae, body orifices. Sometimes it may be a covert one involving non-clinically visible structures such as brain, liver, spleen, endocrine glands. Contrary to other organs, such as gastrointestinal tract, lung, urinary tract, uterus, etc, which communicate with the surface of the human body through ducts or canals, the bleeding in covert organs cannot be seen. It has to be suspected on clinical signs and symptoms and then demonstrated by radiological or surgical procedures [1]. Suprarenal gland hemorrhage belongs to the covert group of bleeding and appears to be frequently underdiagnosed if it is limited to only one of the two glands [2-5].

The condition has been known for many years, but it has drawn great interest only recently since it was noted to occur in clinical entities such as Heparin Induced Thrombocytopenia (HIT) and Antiphospholipids Antibodies Syndrome (APAS) conditions, which have been defined only in the past two decades [6-18]. The purpose of the present review is to deal in a systemic way which suprarenal gland hemorrhage.

\section{Classification, etiology and pathophysiology}

A problem of Semantics has to be clarified. The suprarenal glands are often referred to as Adrenal glands. In our view this is not correct since the term "suprarenal" refers to the entire gland composed of a cortical part and of a medullary part. Adrenal strictly refers only to the medullary part where cathecholamines, including adrenalin, are secreted. Since bleeding may involve the entire gland and not only the medullary part, we think it is correct to use the term suprarenal gland. Another important aspect is the classification of the bleeding in monolateral or bilateral. This has a great importance in diagnosis and management. Finally, another classification concerns the causative mechanisms. These may be summarized in 1) local (tumor, trauma, surgery), 2) systemic (infections, ACTH stimulation, stress), 3) occlusion (thrombosis) or compression of the suprarenal veins. This is an important classification that indicates the variety and complexity of the causes. The main causes of bleeding in suprarenal glands are listed in Table 1.

Of particular interest are the cases observed after partial hepatectomy or liver transplantation. The culprit in these cases is probably trauma, surgical procedures, ligation or blood sampling of suprarenal veins [1927]. In some cases, the bleeding has been maintained to be secondary

Table 1. Main causes of adrenal gland hemorrhage

\begin{tabular}{|l|l|}
\hline 1 & Sepsis (meningococcal infection) \\
\hline 2 & Abdominal trauma and surgery \\
\hline 3 & Hyperstimulation with ACTH \\
\hline 4 & Segmental hepatectomy (monolateral) \\
\hline 5 & Liver transplantation (monolateral) \\
\hline 6 & Hypoxic disorders (neonates) \\
\hline 7 & Anticoagulant therapies \\
\hline 8 & $\begin{array}{l}\text { Thrombosis or occlusion of adrenal and efferent veins (Antiphospholipid antibodies } \\
\text { syndrome, Heparin induced Thrombocytopenia, Polycythemia) }\end{array}$ \\
\hline 9 & Coronary arteries surgical procedures \\
\hline 10 & Persistent stressful conditions \\
\hline 11 & Congenital coagulation disorders \\
\hline 12 & Rupture of aneurysms or tumors (Fheochromocythoma) \\
\hline 13 & Adrenal vein sampling \\
\hline 14 & Idiopathic \\
\hline
\end{tabular}

${ }^{\star}$ Correspondence to: Antonio Girolami, Department of Medicine, University of Padua Medical School, Via Ospedale, 105, Padua, Italy, 35128, Tel: 00390498213026; Fax 0039049657391; Email: antonio.girolami@unipd.it

Received: June 19, 2018; Accepted: June 26, 2018; Published: June 29, 2018 
to thrombosis $[28,29]$. Since bleeding in this case may be monolateral, usually there are no important systemic symptoms and signs. The role of thrombosis in the pathogenesis of suprarenal gland bleeding is still not completely clarified. Because of the especially rich vascularization existing in the gland, it is conceivable that stasis due to vein obstruction may cause upstream increased pressure and rupture of vessels with consequent extravasation of blood. Each gland receives blood from small arteries deriving from the inferior phrenic artery, the abdominal aorta and the renal arteries [30].

These small arteries perforate the capsule and form a rich sub capsular plexus of arterioles. The arterioles irradiate along the "zona fasciculata" to the "zona reticularis" where it forms a deep plexus known as the cortico-medullary dam. This "dam" effect is due to the fact that at the passage between the "zona reticularis" and the medulla, venules show prominent bundles of smooth muscle fibers before entering the medullary vein and then into the central vein. The latter, on the right site, drains into the inferior vena cava (I.V.C.) and, on the left side, into the renal vein $(\mathrm{RV})[30]$

The role of thrombosis in the pathogenesis of suprarenal gland hemorrhage is supported also by the observation that the condition has been reported in patients with congenital thrombophilia [31]. The cases of adrenal gland bleeding after ACTH stimulation observed in clinical practice are of extreme interest. Intramuscular ACTH was widely used 20-30 years ago, now it is seldom used. It is interesting to note that most of the numerous papers dealing with ACTH induced adrenal hemorrhage appeared in that period. It has been proven even in the experimental animal that massive ACTH stimulus increased blood flow to the suprarenal glands [32-34].

Because of the rich vascularization of the gland it is feasible that extravasation may occur. The sporadic cases of adrenal hemorrhage seen in conditions of sustained stress have probably the same origin. We are aware of only one case of adrenal hemorrhage occurring in a hemophilia A patient. The patient was a neonate who showed a hematoma of the right renal gland that caused anemia, dyspnea, abdominal distention. Abdominal sonography was diagnostic. Proper substitution therapy was successful [35]. Another patient with hemophilia A had an aneurysm of an adrenal vein which was confused with a tumor [36].

Contrary to the rarity seen for congenital bleeding disorders, suprarenal gland hemorrhage has been frequently reported during anticoagulant therapy with both heparin and coumarin drugs [2,37-39]. A special form of suprarenal gland hemorrhage has been described in neonates [40,41]. Particularly predisposed are the neonate who are under ExtraCorporeal Membrane Oxygenation (ECMO) procedures [42].

An important consideration in this regard is the double role that heparin has with suprarenal gland bleeding. It can be secondary to the protracted use of intravenous heparin that cause bleeding, but it could also be the result of a Heparin induced thrombocytopenia (HIT) with consequent thrombosis of suprarenal or renal veins [9-11,28]. Sepsis was often reported in the past as a cause of suprarenal gland hemorrhage with consequent catastrophic gland failure [3,38]. Unfortunately, the event may occur even today [43].

Besides the cases that can be attributed to a specific cause, some reports refer to spontaneous or idiopathic hemorrhage. The existence of this form is not proven yet because the absence of risk or triggering conditions have not always been ruled out [44].

\section{Diagnosis}

Diagnostic suspicion of suprarenal gland bleeding may be relatively easy in case of bilateral involvement. On the contrary it may be difficulty because of non-specific clinical and laboratory manifestation, in case of monolateral bleeding. Vague abdominal pain radiating to flank, nausea, vomiting, hypotension, positive history for trauma, recent surgery, systemic conditions as HIT and APAS, are frequent findings (Table 2). From a laboratory standpoint, hypohyponatremia, hyperkalemia and increased BUN are commonest findings. The most critical diagnosis concerns the monolateral vs the bilateral bleeding. On clinical grounds monolateral forms are usually associated with trauma and surgical procedures. On the contrary bilateral or massive forms are secondary to sepsis, prolonged ACTH stimulation, HIT or APAS, namely systemic conditions (Tables 3 and 4). Sonography, CAT and/or MRI are diagnostic [3,5] (Figures 1 and 2). The CAT reveals an isointense or hypointense mass. It has to be remembered that before the introduction of imagine techniques the great majority of cases of monolateral adrenal hemorrhage were diagnosed at autopsy or during exploratory surgery $[2,3,24]$.

Contrary to what occurs for bleeding in other endocrine glands, bleeding in a suprarenal gland and, especially in case of bilateral involvement, systemic, often acute, changes become promptly evident (lethargy, mental confusion, hypotension, severe asthenia, shock).

\section{Management}

The approach varies with the severity of the condition. Since the monolateral lesion is usually benign in evolution, surgical removal should be limited only to cases in which there is, on a CAT control, an increase in the size of the mass. Bilateral forms require prompt

Table 2. Value of signs, symptoms and recent past history in the diagnosis of suprarenal gland hemorrhage

\begin{tabular}{|l|}
\hline Recent abdominal surgery, HIT, APAS, polycythemia \\
\hline Abdominal pain \\
\hline Back and flank pain \\
\hline Chest pain \\
\hline Weakness \\
\hline Nausea, vomiting \\
\hline Hypotension \\
\hline Anorexia \\
\hline Fever \\
\hline Abdominal rigidity and rebound \\
\hline Mental confusion \\
\hline Hypothermia \\
\hline Shock \\
\hline
\end{tabular}

Table 3. Pathogenetic mechanisms of suprarenal gland hemorrhage

\begin{tabular}{|c|c|c|}
\hline 1. Primitive or direct damage & $\begin{array}{c}\text { 2. Secondary damage due to } \\
\text { thrombosis of efferent veins }\end{array}$ & 3. Idiopathic \\
\hline Sepsis & HIT & \\
\hline ACTH administration & APAS & \\
\hline Hypoxemia (neonate) & Congenital thrombophilia & \\
\hline Local trauma or surgery & Polycythemia & \\
\hline
\end{tabular}

Table 4. Differential diagnosis of types of Suprarenal hemorrhage

\begin{tabular}{|c|c|}
\hline Monolateral & Bilateral \\
\hline Often asymptomatic,or paucisymptomatic & Always clearly symptomatic \\
\hline Often an incidental report & Sepsis \\
\hline Complication of kidney surgery & HIT, APAS \\
\hline Complication of gall bladder surgery & ACTH administration \\
\hline
\end{tabular}




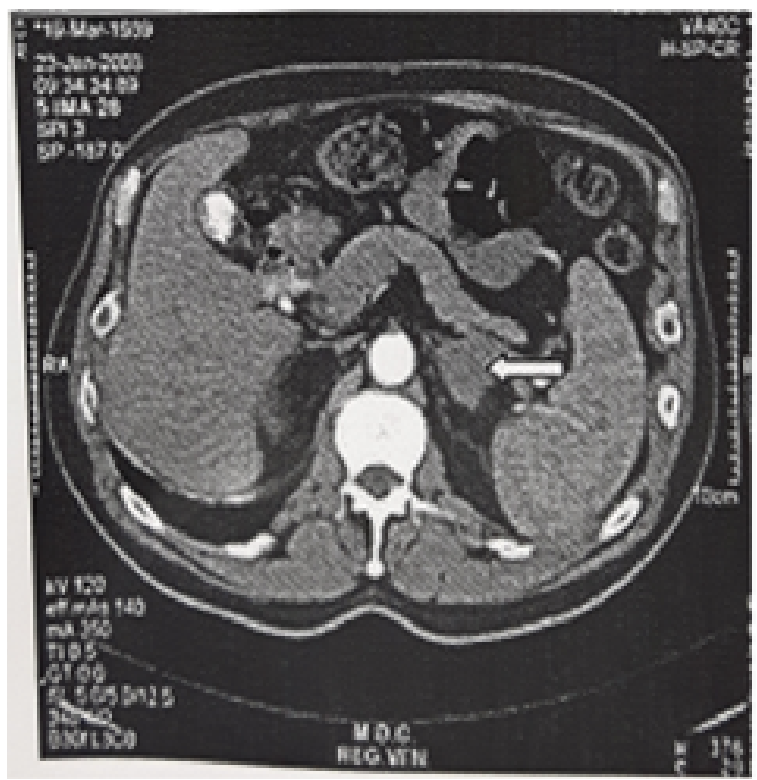

Figure 1. CAT image of a left-side suprarenal gland hemorrhage. Enlarged gland is indicated by an arrow. The patient had Antiphospholipid antibodies syndrome (APAS) and showed a recovery

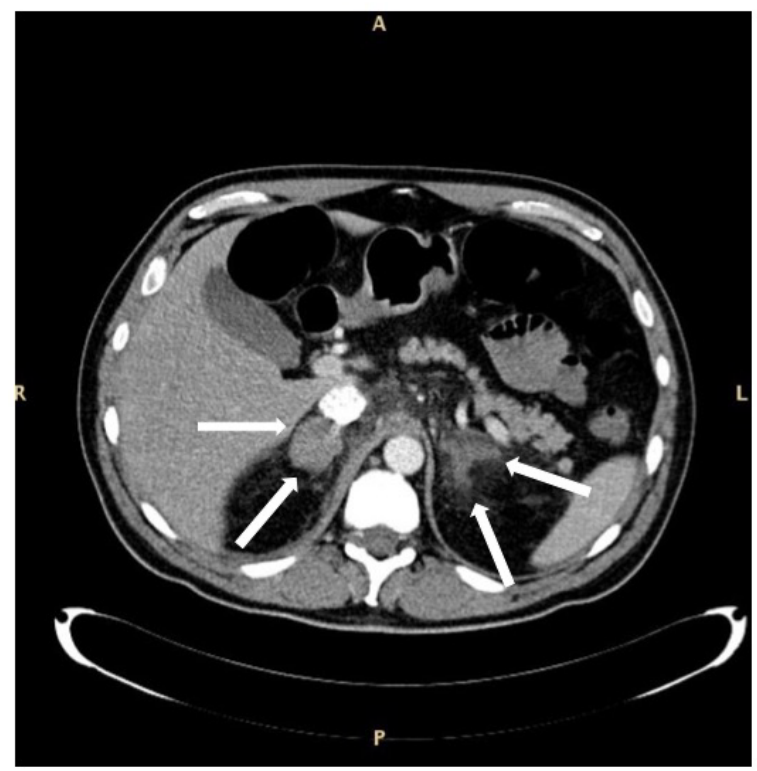

Figure 2. CAT of a bilateral suprarenal gland hemorrhage in a patient with sepsis and myelodysplastic syndrome with excess blasts type 1 . The enlarged glands are indicated by arrows. The aspect of the right gland appears more uniform as compared with that of the left one. Patient survived

administration of cortisone and strict ions surveillance. Blood pressure should be maintained with plasma expanders and fluids. Specific measures may be required in certain cases (for example, antibiotics in case of sepsis).

\section{Prognosis}

Prognosis is variable, depending on the extension of the involvement, monolateral or bilateral. Monolateral involvement has usually a good prognosis even without therapy but for patients with clotting disorders. Bilateral, massive hemorrhage is an acute, serious event associated in the past with frequent fatalities. Recent diagnostic procedures as CAT or MRI have allowed a prompt diagnosis thereby improving the prognosis. Fatalities are now rare.

\section{Conclusions}

The first observation on Suprarenal Glands bleeding refers to the rarity of the event among congenital bleeding disorders. Only one patient with Hemophilia A has been reported [35].

This is more so when one considers that these patients are at present time frequently investigated by CAT or MRI. It is likely that minor suprarenal grand hemorrhages in patients with congenital clotting factor deficiency go undetected because of the most important overt bleeding manifestations (hematuria, hematomas, hemarthrosis, gastro-intestinal bleeding) seen in these patients. On the contrary, anticoagulant therapy may be associated with suprarenal gland bleeding. Both heparin and coumarin drugs have been implicated [37-39]. However, it has to be remembered that an important cause of suprarenal gland bleeding is rupture of small arteries or capillaries secondary to impairment in blood flow due to thrombotic obstructions in the adrenal veins. Since thrombosis is exceptional in congenital bleeding disorders [45,46], this could also explain the rarity of suprarenal gland bleeding in congenital coagulation disorders.

This paucity of observation may indicate that the pathogenesis of suprarenal gland bleeding is often due to thrombotic occlusion of the central vein with upstream stasis and bleeding due to rupture of small arterial vessels. This is what occurs in the present-day cases of suprarenal gland hemorrhage due to HIT and APAS. Post-surgery or post-trauma cases are probably due to direct damage to venous and arterial vessels without stasis due to vein occlusions. In the old cases due to adrenal hyperstimulation secondary to ACTH administration, a direct damage to cells was involved. The same direct damage was also involved in the premature, hypoxic newborn during the attempt at oxygenation therapy $[40,42]$.

It is interesting to note that pathogenetic mechanism may be varied but the result is the same, namely destruction of gland tissue with consequent failure. The bleeding may involve different areas of the gland (cortex or medulla) with consequent discrepant decrease of hormones. Since the main action of suprarenal gland hormones (aldosterone, adrenalin, etc) control blood pressure, their deficiency causes hypotension and shock. That may be acute, subacute or chronic according to the rate and degree of adrenal damage. The recent cases observed during HIT or APAS and due to thrombotic occlusion of the adrenal veins with consequent upstream stasis and congestion have received the interest of clinicians. It is important today, in the contest of these immunological syndromes, to pay due attention to abdominal signs and symptoms and flank pain, nausea, vomiting, hypotension, weakness. In the presence of any of these signs and symptoms, a radiological investigation of the suprarenal glands is absolutely indicated.

Even the cases observed in Polycythemia are probably due to impaired venous drainage or thrombosis due to the hyperviscosity of blood [29]. The role carried out by venous obstructions is a new pathogenetic element in the study and management of suprarenal gland hemorrhage. Physicians caring for patients with HIT or APAS should be alert about the possibility that such conditions could be responsible for suprarenal gland bleeding. It is likely that even the so called idiopathic cases of suprarenal gland hemorrhage [44] might represent unrecognized cases due to thrombosis. 


\section{Acknowledgments}

The paper has been carried out according to the Helsinki convention. This study was supported in part by the "Associazione Emofilia ed altre coagulopatie delle Tre Venezie".

\section{References}

1. Girolami A, Luzzatto G, Varvarikis C, Pellati D, Sartori R, et al. (2005) Main clinical manifestations of a bleeding diathesis: an often disregarded aspect of medical and surgical history taking. Haemophilia 11: 193-202. [Crossref]

2. Editorial (1966) Adrenal haemorrhage and anticoagulants. Br Med J 19: 693-694.

3. Vella A, Nippoldt TB, Morris JC 3rd (2001) Adrenal hemorrhage: a 25-year experience at the Mayo Clinic. Mayo Clin Proc 76: 161-168. [Crossref]

4. Dahlberg PJ, Goellner MH, Pehling GB (1990) Adrenal insufficiency secondary to adrenal hemorrhage. Two case reports and a review of cases confirmed by computed tomography. Arch Intern Med 150: 905-909. [Crossref]

5. Miele V, Patti G, Cappelli L, Calisti A, Valenti M (1994) [Echography in the diagnosis of neonatal adrenal hemorrhage]. Radiol Med 87: 111-117. [Crossref]

6. Arthur CK, Grant SJ, Murray WK, Isbister JP, Stiel JN, et al. (1985) Heparin-associated acute adrenal insufficiency. Aust N Z J Med 15: 454-455. [Crossref]

7. Bakaeen FG, Walkes JC, Reardon MJ (2005) Heparin-induced thrombocytopenia associated with bilateral adrenal hemorrhage after coronary artery bypass surgery. Ann Thorac Surg 79: 1388-1390.

8. Caron P, Chabannier MH, Cambus JP, Fortenfant F, Otal F, et al. (1988) Definitive Adrenal Insufficiency Due to Bilateral Adrenal Hemorrhage and Primary Antiphospholipid Syndrome. J Clin Endocrinol Metab 83: 1437-1439. [Crossref]

9. Delhumeau A, Houet JF, Bourrier P, Bukowski JG, Granry JC (1989) Heparin-induced thrombocytopenia complicated by hematoma of the adrenal glands and acute adrenal insufficiency. Ann Fr Anesth Reanim 8: 656-658. [Crossref]

10. Echániz A, Diz-Lois F, Pellicer C, Sanmartín J, Suárez Dono I, et al. (1992) [Bilateral adrenal hemorrhage secondary to heparin treatment: a case report]. An Med Interna 9: 189-191. [Crossref]

11. Kurtz LE, Yang S (2007) Bilateral adrenal hemorrhage associated with heparin induced thrombocytopenia. Am J Hematol 82: 493-494. [Crossref]

12. Lê TH, Wechsler B, Piette JC, Doumith R, Bellin MF, et al. (1993) [Antiphospholipid syndrome. A new cause of bilateral hemorrhage of the adrenal glands. 4 cases]. Presse Med 22: 249-254. [Crossref]

13. Presotto F, Fornasini F, Betterle C, Federspil G, Rossato M (2005) Acute adrenal failure as the heralding symptom of primary antiphospholipid syndrome: report of a case and review of the literature. Eur J Endocrinol 153: 507-514. [Crossref]

14. Reverdy F, Freichet M, Grozel JM, Tassin C, Pirio V (2013)Thrombose hémorragique bilatérale des surrénales dans les suites d'une thrombopénie induite par héparine de type 2 : une cause d'état de choc méconnue. Annales francaises d'anesthesie et de reanimation 32: 206-207.

15. Rosenberger LH, Smith PW, Sawyer RG, Hanks JB, Adams RB, et al. (2011) Bilateral adrenal hemorrhage: the unrecognized cause of hemodynamic collapse associated with heparin-induced thrombocytopenia. Crit Care Med 39: 833-838. [Crossref]

16. Saleem N, Khan M, Parveen S, Balavenkatraman A(2016) Bilateral adrenal haemorrhage: a cause of haemodynamic collapse in heparin-induced thrombocytopaenia. BMJ Case Rep 10. [Crossref]

17. Santonastaso M, Bovo P, Colaceci R, Corbanese U, Ruga P (1993) Acute adrenal failure due to adrenal hemorrhagic necrosis secondary to heparin-induced thrombocytopenia. Recenti Prog Med 84: 687-690. [Crossref]

18. Warkentin TE, Safyan EL, Linkins LA (2015) Heparin-Induced Thrombocytopenia Presenting as Bilateral Adrenal Hemorrhages. N Engl J Med 372: 492-494. [Crossref]

19. Gouliamos AD, Metafa A, Ispanopoulou SG, Stamatelopoulou F, Vlahos LJ, et al. (2000) Right adrenal hematoma following hepatectomy. European Radiology 10: 583-585. [Crossref]

20. Hochheim B, Liedloff H, Franke J (1985) [Fatal adrenal gland hemorrhage after implantation of a total endoprosthesis and anticoagulant therapy]. Beitr Orthop Traumatol 32: 287-289.
21. Ikekpeazzu N, Bonadies JA, Sreenivas VI (1996) Acute bilateral adrenal hemorrhage secondary to rough truck ride. J Emerg Med 14: 15-18. [Crossref]

22. Lehrberg A, Kharbu B (2017) Isolated unilateral adrenal gland hemorrhage following motor vehicle collision: a case report and review of the literature. J Med Case Rep 11: 358. [Crossref]

23. Liessi G, Sandini F, Semisa M, Spaliviero B (1988) [Traumatic hematomas of the adrenal glands: CT and US findings in 3 cases]. Radiol Med 76: 610-613. [Crossref]

24. Rao RH (1995) Bilateral massive adrenal hemorrhage. Med Clin North Am 79: $107-$ 129. [Crossref]

25. Sutherland FW, Naik SK (1996) Acute adrenal insufficiency after coronary artery bypass grafting. Ann Thorac Surg 62: 1516-1517. [Crossref]

26. Winter AG, Ramasamya R (2014) Bilateral adrenal hemorrhage due to heparin-induced thrombocytopenia following partial nephrectomy - a case report. Fl000Res 3: 24 [Crossref]

27. Hannah-Shmouni F, Demidowich A, Alves BR, Paluch GD, Margarita D, Lysikatos C, et al. (2017) Management of primary aldosteronism in patients with adrenal hemorrhage following adrenal vein sampling: A brief review with illustrative cases. $J$ Clin Hypertens (Greenwich) 19: 1372-1376. [Crossref]

28. Tattersall TL, Thangasamy IA, Reynolds J (2014) Bilateral adrenal haemorrhage associated with heparin-induced thrombocytopaenia during treatment of Fournier gangrene. BMJ Case Rep. [Crossref]

29. Bhandari S, Agito K, Krug E (2016) Bilateral adrenal hemorrhage in polycythemia vera. J Community Hosp Intern Med Perspect 6: 32416. [Crossref]

30. Williams PL, Warwick R. (Editors) (1980) Gray's Anatomy. Churchill Livingstone, Edinburgh, 36th Edition, pag. 1456.

31. Brill PW, Jagannath A, Winchester P, Markisz JA, Zirinsky K (1989) Adrenal hemorrhage and renal vein thrombosis in the newborn: MR imaging. Radiology 170: 95-98. [Crossref]

32. Leret N, Cortey A, Maillard C, Rouabah M, Hascoët JM, et al. (2001) [Neonatal renal vein thrombosis in a heterozygous carrier of both factor $\mathrm{V}$ Leiden and prothrombin mutations]. Arch Pediatr 8: 1222-1225. [Crossref]

33. Dunlap SK, Meiselman MS, Breuer RI, Panella JS, Ficho TW, et al. (1989) Bilateral adrenal hemorrhage as a complication of intravenous ACTH infusion in two patients with inflammatory bowel disease. Am J Gastroenterol 84: 1310-1312. [Crossref]

34. Marcus HI, Connon JJ, Stern HS (1986) Bilateral adrenal hemorrhage during ACTH treatment of ulcerative colitis. Report of a case and review of the literature. Dis Colon Rectum 29: 130-132. [Crossref]

35. Le Pommelet C, Durand P, Laurian Y, Devictor D (1998) Haemophilia A: two cases showing unusual features at birth. Haemophilia $4: 122-125$. [Crossref]

36. Sleightholm R, Wahlmeier S, Carson JS, Drincic A, Lazenby A, et al. (2016) Massive adrenal vein aneurysm mimicking an adrenal tumor in a patient with hemophilia A: a case report and review of the literature. J Med Case Rep 10: 343. [Crossref]

37. Ognibene AJ, McBride H (1987) Adrenal hemorrhage: a complication of anticoagulant therapy--a case history. Angiology 38: 479-483. [Crossref]

38. Rao RH, Vagnucci AH, Amico JA (1989) Bilateral massive adrenal hemorrhage: early recognition and treatment. Ann Intern Med 110: 227-235. [Crossref]

39. Scully RE, Mark EJ, McNeely WF (1989) Case records of the Massachusetts General Hospital. N Engl J Med 321: 1595-1603.

40. Ausserer O, Ortore PG, Sarra A, von Fioreschy G (1983) Adrenal hemorrhage in the newborn. Prog Pediatr Surg 16: 107-111. [Crossref]

41. Heyman S, Treves S (1979) Adrenal hemorrhage in the newborn: scintigraphic diagnosis. J Nucl Med 20: 521-523. [Crossref]

42. Sivit CM, Short BL, Revenis ME, Rebolo LC, Brown-Jones C, et al. (1993) Adrenal hemorrhage in infants undergoing ECMO: prevalence and clinical significance. Pediatr Radiol 23: 519-521. [Crossref]

43. Khwaja J (2017) Bilateral adrenal hemorrhage in the background of Escherichia coli sepsis: a case report. J Med Case Rep 11: 72. [Crossref]

44. Dhawan N, Bodukam VK, Thakur K, Singh A, Jenkins D, et al. (2015) Idiopathic bilateral adrenal hemorrhage in a 63-year-old male: a case report and review of the literature. Case Rep Urol 2015: 503638. [Crossref] 
45. Girolami A, Ruzzon E, Fabris F, Varvarikis C, Sartori R, et al. (2006) Myocardial infarction and other arterial occlusions in hemophilia a patients. A cardiological evaluation of all 42 cases reported in the literature. Acta Haematol 116: 120-125. [Crossref]
46. Girolami A, Ruzzon E, Tezza F, Scandellari R, Vettore S (2006) Arterial and venous thrombosis in rare congenital bleeding disorders: a critical review. Haemophilia 12: 345-351. [Crossref]

Copyright: (C2018 Girolami A. This is an open-access article distributed under the terms of the Creative Commons Attribution License, which permits unrestricted use, distribution, and reproduction in any medium, provided the original author and source are credited. 